\title{
Immuno-reconstitution by thymic transplant in DiGeorge's syndrome
}

\begin{abstract}
S. R. DAGA
M.D.

M. P. LOKHANDE

M.B.B.S.

P. G. PRABHU

M.B.B.S.

\section{Summary}

Persistent hypocalcaemic tetany in a breast-fed neonate made us suspect DiGeorge's syndrome, particularly as the baby had an abnormal facies, and a ventricular septal defect. Immuno-reconstitution was successfully achieved by thymic transplant. Evidence of immuno-reconstitution on the basis of the histology of the post-transplant thymus has not been previously recorded.
\end{abstract}

\author{
H. M. SIDDIQUI \\ M.D.
}

L. CHANDRASHEKHAR

M.B.B.S.

B. N. KANSARIA

M.B.B.S.

Departments of Paediatrics and Pathology, Grant Medical College and J.J. Group of Hospitals, Bombay-400 008, India

KEY WORDS: T-cell immunodeficiency, hypocalcaemia, hypoparathyroidism, ventricular septal defect.

\section{Introduction}

DiGeorge's syndrome results from an interference in embryogenesis between the sixth and tenth week of intrauterine life, involving the third and fourth branchial arches; the first and second arches are often and the sixth arch occasionally involved. The association of congenital absence of the thymus with seizures in the newborn and abnormal third and fourth pharyngeal pouch development was recorded long ago (Harrington, 1829). The association of defective immunological status with maldeveloped branchial arches and tetany was described by DiGeorge (1965). Additional cases were reported later on (Taitz, Zarate-Salvador and Schwartz, 1966; Huber, Cholnoky and Zoethut 1967; Kietschmer et al., 1968a).

Three major variants of DiGeorge's syndrome have been described. A complete form in which the thymus is absent, an 'incomplete' form in which the thymus is severely hypoplastic and a transient form.

\footnotetext{
* Reprints from: Institute of Child Health, J.J. Group of Hospitals, Bombay-400 008, India.
}

Congenital heart disease and hypoparathyroidism are always present (Stiehm and Fulginiti, 1980). DiGeorge's syndrome was confirmed as a unique disorder especially after immuno-reconstitution was achieved by fetal thymic transplants (August et al., 1968; Cleveland et al., 1968). We report a case with post-thymic transplant findings at autopsy.

\section{Case report}

A full-term $3 \mathrm{~kg}$ male infant was born vaginally to a primigravida following premature rupture of membranes 7 days previously. Examination revealed a hypothermic baby in respiratory distress. The baby had an abnormal facies with receding chin, low set ears and fish-like mouth (Fig. 1). White blood cell count was $4.2 \times 10^{9} / 1$ with lymphocytes $42 \%$. Blood and cerebrospinal fluid culture grew Escherichia coli.

On the third day a short systolic murmur grade IIIIV was heard in the left third intercostal space. The baby also had multifocal convulsions. Serum calcium was $6.9 \mathrm{mg} / \mathrm{dl}$, and serum phosphorus $5.2 \mathrm{mg} / \mathrm{dl}$. Chest X-ray revealed cardiomegaly and the absence of thymic shadow. The child received diuretics, digitalis, and intravenous calcium gluconate followed by oral calcium.

By the 5th day, convulsions ceased, respiratory distress was alleviated considerably, and the liver, previously swollen, regressed to its original size. On the 10th day, calcium was discontinued. Thereafter the convulsions recurred, and the serum calcium was found to be $7 \cdot 1 \mathrm{mg} / \mathrm{dl}$. Serum phosphorus was 4.9 $\mathrm{mg} / \mathrm{dl}$. Convulsions again responded promptly to calcium therapy, but recurred once again on the 21 st day after discontinuing calcium for 2 days. The baby started gaining weight moderately and steadily. 


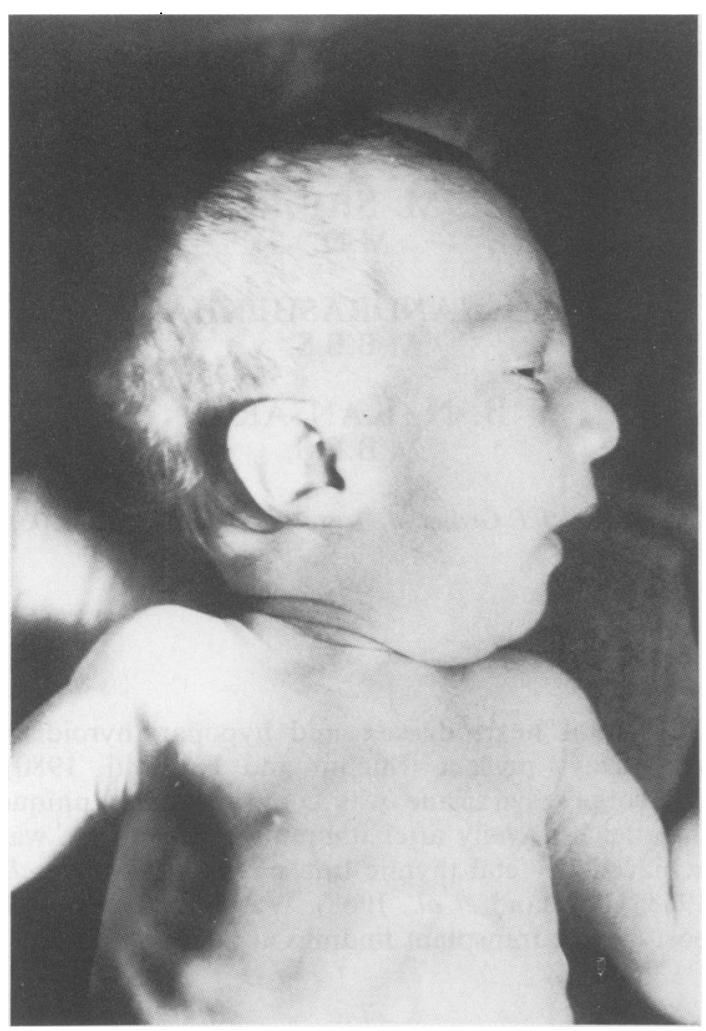

FIG. 1. DiGeorge's syndrome shows abnormal facies with receding chin and low set ears.

With the possibility of DiGeorge's syndrome in mind the following investigations were carried out on the 21 st day of life. White cell count $10.2 \times 10^{9} / 1$, with neutrophils $45 \%$, lymphocytes $50 \%$, monocytes $3 \%$ and eosinophils $2 \%$. Chest X-ray revealed the absence of a thymus. Erythrocyte rosette count (ERC) was $10 \%$ (normal range $60-80 \%$ ). Immunoglobulin estimations revealed IgA $90 \mathrm{mg} / \mathrm{dl}$ (normal range 8-34 mg/dl), IgM $70 \mathrm{mg} / \mathrm{dl}$ and IgG $500 \mathrm{mg} / \mathrm{dl}$ (normal range 311-549 mg/dl). Radioimmunoassay for hormones revealed parathyroid hormone (PTH) $0.08 \mathrm{ng} / \mathrm{ml}(2.4 \mu \mathrm{Eq} / \mathrm{ml}), \mathrm{M}$ mode echocardiogram was normal.

Thus thymic hypoplasia and hypoparathyroidism were confirmed. Invasive studies to confirm the cardiac diagnosis were deferred till immuno-reconstitution was achieved. Fetal thymus was obtained from a medical termination of a 16 week's pregnancy. It was transplanted in the patient's rectus sheath on the 60 th day of life. Four days after the transplant, the erythrocyte vosette count was still $10 \%$. White cell count was $8.2 \times 10^{9} / 1$, with lymphocytes $40 \%$. One possible reason for the failure of transplant may be that the abortion took place after $18 \mathrm{hr}$ of intra- amniotic injection of saline. Another attempt at 2 thymic transplant was made on the 87th day. This time, fetal thymus was obtained from a hysterotomy product of an 18-week pregnancy and was trans- $\Rightarrow$ planted within minutes. The ERC rose to $36 \%$ by the 3rd day of transplant.

By this time convulsions were fully under control흔 with calcium and vitamin D. Chest X-ray showed $\frac{\bar{N}}{\vec{D}}$ prominent pulmonary conus and peripheral attenua- $\stackrel{\mathbb{}}{\Omega}$ tion of vascular markings. Serial electrocardiograms showed progressive pulmonary hypertension and right ventricular hypertrophy. On the 95th day the child developed a lower respiratory infection and $\vec{\omega}$ died suddenly on the 105th day.

\section{Autopsy findings}

A small mass $(2.5 \times 1.5 \times 0.5 \mathrm{~cm})$, situated just. above the right side of aortic arch was identified as rudimentary thymus. A few small lymph nodes, the largest $1 \mathrm{~cm}$ in diameter, were observed only in the superior mediastinum and mesentery. The spleen was 0 moderately enlarged and firm. The site of the first thymic transplant in the right rectus sheath was unremarkable. At the site of the second thymico transplant in the left rectus sheath, a small flattened nodule was felt which appeared whitish and homogenous on sectioning. The lobulated thymic tiss: showed few Hassall's corpuscles, and relatively abu dant lymphoid tissue consisting of normal, matue lymphocytes. There was no cortiomedullary differentiation (Fig. 2).

Lymph nodes, spleen, tonsils and the Peyer's气 patches revealed poorly developed lymphoid tissue $\stackrel{\circ}{\stackrel{D}{\perp}}$ with absence of germinal centres.

Both the transplanted tissues were converted into eosinophilic hyaline masses with no recognisable? thymic tissue. There was no inflammatory reaction? around the first transplant but the second transplant showed hyperaemia and lymphocytic and mononu- 3 clear infiltration around it. Plasma cell infiltration and vasculitis were absent.

The thyroid, normal in size, consisted of twoo separate lobes, without an isthmus. Even after a thorough inspection and subsequent study of severalo $2 \mathrm{~mm}$ thick, horizontal slices of thyroid, larynx and trachea with a dissecting microscope, no trace of parathyroid glands could be found. There was a high
ventricular septal defect.

\section{Discussion}

Our patient had all the characteristic features of DiGeorge's syndrome in the form of abnormal facies, severely hypoplastic thymus, T-cell immunodeficiency, hypoparathyroidism and congenital cardiac defect. The absence of thyroid isthmus was another manifestation of DiGeorge's syndrome. 


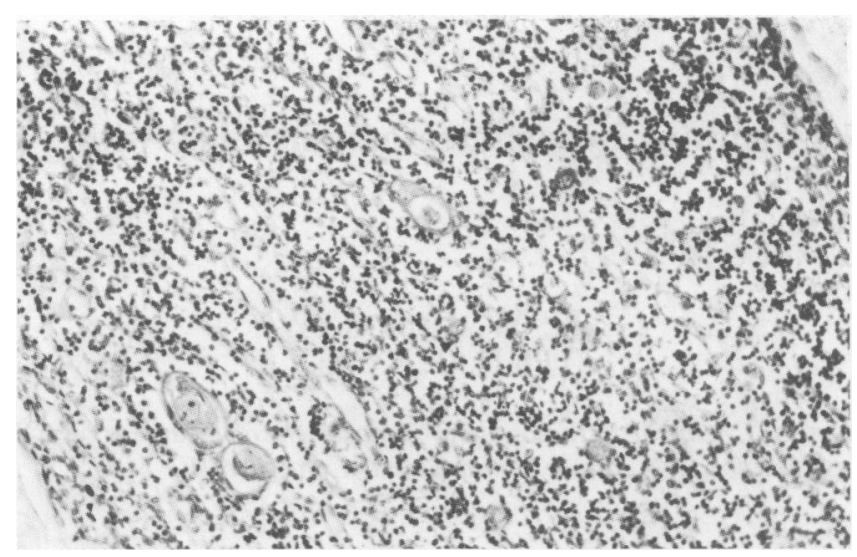

Fig. 2. Thymus with few Hassall's corpuscles and uniformly distributed lymphoid tissue without corticomedullary differentiation (H \& E $\times 150)$.

In view of the microscopic appearance of lymphoid tissue, stress involution of thymus and graft versus host disease (GVHD) were considered in the differential diagnosis. The baby was born with an average birth weight and had been growing normally. The early neonatal infection was adequately treated. Hence stress involution could not have persisted up to the 105th day. GVHD was less likely in the absence of hepatosplenomegaly, lymphadenopathy, diarrhoea and characteristic cutaneous lesions. The histological appearance of skin, lungs and liver also did not support the diagnosis of GVHD. Moreover, the estimated maturity of the transplanted thymus was around 18 weeks, which also precludes the likelihood of GVHD by the transplant although delayed manifestation of GVHD cannot be ruled out. Finally, the absence of demonstrable parathyroid tissue and the thyroid isthmus and the presence of a cardiac defect, in conjunction with the observed gross and microsopic changes in the lymphoid tissue of our case, leave no doubt about the existence of $\mathrm{Di}$ George's syndrome, and rule out any possibility of stress involution of thymus or GVHD.

We had achieved a good control of hypocalcaemia and a successful immunoreconstitution. The evidence of the latter was offered by the significant inflammatory reaction evoked by the second graft as against no reaction around the first one. Perhaps the host could have reacted to the graft only after immunoreconstitution which is known to occur within $6 \mathrm{hr}$ of transplant (Stiehm and Fulginiti, 1980). In the past there have been few opportunties to study posttransplant thymus histologically to enable comparison with our findings. These changes are supported by the E-rosette test which by itself is not an infallible measure of the $T$ cell function.

Thymic transplant remains the treatment of choice for $T$ cell immunodeficiency. Thymosin-responsive and thymosin nonresponsive forms of DiGeorge's syndrome have been described (Stiehm and Fubiniti, 1980). Transfer factor is yet to be used in these cases. However, the baby died suddenly before the ventricular septal defect could be diagnosed and corrected surgically. Sudden death has been described in two other cases (Pabst et al., 1976).

\section{Acknowledgments}

The authors wish to thank Dr A. G. Desai and Dr U. L. Wagholikar for their useful suggestions and the Dean, GMC Bombay for his permission to publish the material.

\section{References}

August, C.S., LeVery, R.H., BeRKel, A.I. \& ROSEN, F.S. (1968) Implantation of a foetal thymus, restoring immunological competence in a patient with thymic aplasia (DiGeorge's syndrome) Lancet, ii, 1210.

Cleveland, W.W., Fogel, B.J., Brown, W.T. \& KaY, H.E.M. (1968) Foetal thymic transplant in a case of DiGeorge's syndrome. Lancet, ii, 1211.

DiGeORGE, A.M. (1965) A new concept of the cellular basis of immunity. Journal of Pediatrics, 67, 907.

HARRINGTON, H. (1829) Absence of the thymus gland. London Medical Gazette, 3, 314.

Huber, J., Cholnoky, P. \& Zoethut, H.E. (1967) Congenital aplasia of parathyroid glands and thymus. Archives of Disease in Childhood, 42, 190.

Kretschmer, R., SAy, B., Brown, D. \& Rosen, F.S. (1968a) Congenital aplasia of the thymus gland (DiGeorge's syndrome). New England Journal of Medicine, 279, 1295.

PABST, H.F., WRIGHT, W.C., LeRICHE, J. \& STIEHM, E.R. (1976) Partial DiGeorge's syndrome with substantial cell-mediated immunity. American Journal of Diseases of Children, 130, 316.

STIEHM, E.R. \& FULGINITI, V.A. (1980) Immunologic Disorders in Infants and Children. 2nd edn. W.B. Saunders, Philadelphia.

TAITZ, L.S., ZaraTe-Salvador, C. \& SchwarTZ, E. (1966) Congenital absence of the parathyroid and thymus glands in an infant (III and IV pharyngeal pouch syndrome). Pediatrics, 38, 412.

(Accepted 21 July 1983) 